\title{
Statyba
}

\section{A MEASUREMENT OF THE CONFIGURATION OF A BUILDING ENTERPRISE MANAGEMENT STRUCTURE}

\section{R. Ginevičius}

To cite this article: R. Ginevičius (1996) A MEASUREMENT OF THE CONFIGURATION OF A BUILDING ENTERPRISE MANAGEMENT STRUCTURE, Statyba, 2:7, 60-63, DOI: 10.1080/13921525.1996.10531657

To link to this article: https://doi.org/10.1080/13921525.1996.10531657

曲 Published online: 26 Jul 2012.

Submit your article to this journal

山 Article views: 55 


\section{STATYBOS İMONĖS VALDYMO STRUKTŪROS KONFIGŪRACIJOS MATAVIMAS}

\section{R. Ginevičius}

\section{1. İvadas}

Šiuo metu žinoma keletas požiūriy̨ i efektyvių organizacinių valdymo struktūrų (OVS) formavimą. Naujausias, situacinis, skelbia, kad bet kurių valdymo metodu tinkamumas priklauso nuo konkrečios situacijos. Organizacijos veiklą sąlygoja daugybè išorinių ir vidinių veiksnių, todèl negali būti "geriausio" būdo ją valdyti. Reikia ieškoti tokio, kuris labiausiai tinka konkrečiomis sąlygomis [1, 2].

Situacinis požiūris $\mathfrak{i}$ valdymą yra naujas, todèl dar ne visi konceptualūs klausimai išspręsti iki galo. Vienas jų - situacijos, valdymo objekto ir subjekto santykis. Apie tai literatūroje, ypač vakarietiškoje, užsimenama tik netiesiogiai. Pavyzdžiui, teigiama, kad valdymo subjekto paskirtis - užtikrinti efektyvu valdymo objekto darbą. Taip pat nurodoma, kad dauguma specialistu visą kompanijos veiklą pradeda nagrinèti nuo valdymo objekto ir pan. [3, 4]. Daugelyje kitų tyrimų vienareikšmiai sakoma, kad tobulinant imonès OVS sèkmès galima tikètis tik tada, kai imonès valdymo sistema (VS) formuojama ir funkcionuoja tiesiogiai susieta su gamybine sfera. Valdymo tobulinimo tikslai turi būti nustatomi įvertinant pirmiausia gamybos vystymąsi, todèl ir pačią VS reikia kurti atsižvelgiant $\mathfrak{i}$ gamybos veiksnius. Taigi valdymo subjekto mastai ir struktūra turi priklausyti nuo valdymo objekto mastų ir struktūros, ir kisti VS turi priklausomai nuo pokyčiu įmonès gamybinèje sferoje (1 pav.) [5].

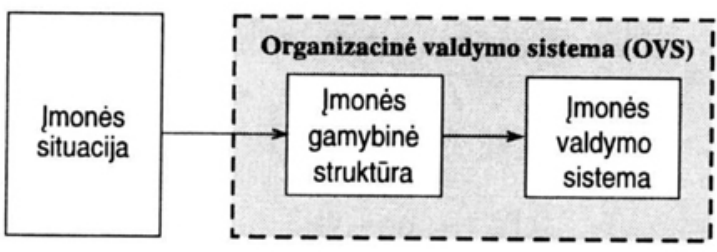

1 pav. Imonès valdymo sistemos tobulinimo konceptualus modelis

Fig. 1. Conceptual model of enterprise management system improvement
Iš 1 pav. matome, kad tobulinant imonès valdymo sistemą pirmiausia reikia nustatyti ir kiekybiškai išreikšti jos dimensijas. Organizacijos teorija išskyrè ir gana nuodugniai išnagrinejjo du pagrindinius principus, kuriais remiasi visų OVS formavimas, - specializavimą ir koordinavimą. Mažiau dèmesio skiriama išorinei įmonès valdymo struktüros formai, prie kurios veda šie du mechanizmai - konfigūracijai, arba tiesiog valdymo sistemai. Ji apibrèžiama kaip požymių, pasireiškiančiu organizacijos diagramoje (organigramoje), visuma [1].

\section{Statybos ịmoniy valdymo struktūros konfigūracijos matavimas}

Nežiūrint i tai, kad pastaruoju metu organizacijose, kurios susiduria su staigiai besikeičiančiomis išorinèmis sąlygomis arba kai igyvendinami sudètingi projektai, o technologija vystosi labai intensyviai, pradétos taikyti adaptyvios struktūros (projektinè, matricinè ir pan.), galima teigti, kad gamybinès paskirties imonèse vyrauja funkcinė ir divizinė valdymo sistemos. Ju matavimui empiriniuose tyrimuose dažniausiai naudojami valdymo piramides skaidymo gylis ir plotis, kartais - santykiai tarp įvairių pareigybiu rūšių [1].

Konkreti skirstymo i hierarchinius valdymo lygius išraiška yra ju skaičius. Šio dydžio nustatymas visai organizacijai yra problemiškas, kadangi ịvairiose jos baruose jis gali būti nevienodas. Siūlomi keli sprendimo būdai: arba imti didžiausią klasifikavimo gyli, t.y. hierarchinių valdymo lygių skaičių labiausiai sudalintame bare, arba nustatyti vidutinį jų skaičių. Ieškant šio dydžio galima remtis įmonès VS grafiniu atvaizdu (organigrama) (2 pav.).

Kaip matome iš 1 pav., baruose valdymo lygių skaičius yra skirtingas ir vyrauja vienalinijinès valdymo sistemos atvejis, labiausiai šiuo metu paplitęs praktikoje. Jai būdinga tai, kad nurodymų santykiai formuojami taip, jog aukštesnè tarnyba gali duoti nurodymus kelioms žemesnèms tarnyboms, bet kiekviena iš ju juos gauna tik iš vienos aukštesnio lygio tarnybos. 
1 lygis
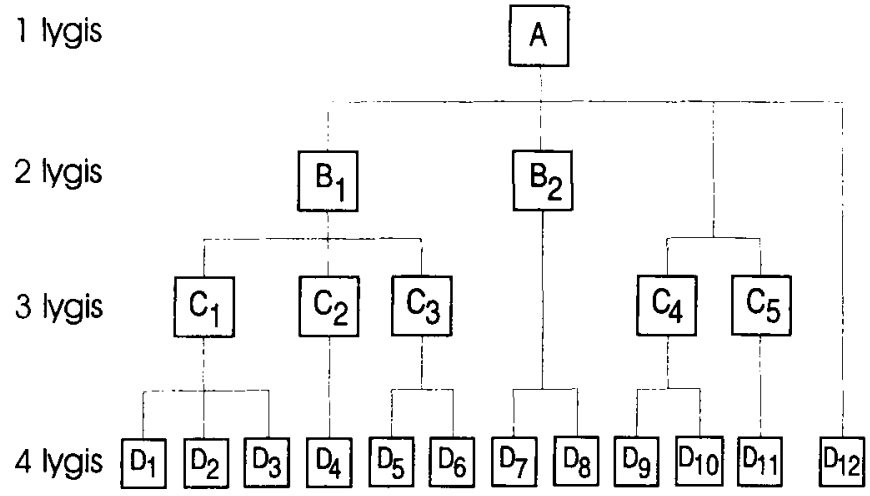

2 pav. Imonès valdymo sistemos organigrama

Fig. 2. Organigram of enterprise management system

İvertinus šią aplinkybę, organizacijos valdymo sistema vertikaliomis atkarpomis vaizduojama 1 lenteleje.

Toks VS vaizdavimas leidžia jos struktūrą užrašyti kaip matricą $\mathbf{M}_{k}$, kurios stulpeliy skaičius yra lygus vertikalių atkarpų kiekiui (padalinių skaičiui žemiausiame lygyje), o eilučì skaičius - didžiausiam valdymo hierarchiniụ lygiụ skaičiui (mūsų nagrinejjamu atveju - keturiems). Kiekviena instancija, esanti vertikalioje atkarpoje, igauna reikšmę 1 , jei kuriame nors hierarchiniame lygyje jos nèra - reikšmę 0 .

Atveju, parodytu 1 lentelèje, matricą $\mathbf{M}_{k}$ galima užrašyti taip:

$$
\begin{array}{llllllllllll}
1 & 2 & 3 & 4 & 5 & 6 & 7 & 8 & 9 & 10 & 11 & 12
\end{array}
$$

$\mathbf{M}_{k}=\frac{1}{2}\left[\begin{array}{llllllllllll}2 & 1 & 1 & 1 & 1 & 1 & 1 & 1 & 1 & 1 & 1 & 1 \\ 1 & 1 & 1 & 1 & 1 & 1 & 1 & 1 & 0 & 0 & 0 & 0 \\ 1 & 1 & 1 & 1 & 1 & 1 & 0 & 0 & 1 & 1 & 1 & 0 \\ 1 & 1 & 1 & 1 & 1 & 1 & 1 & 1 & 1 & 1 & 1 & 1\end{array}\right]$

Vidutini hierarchiniu valdymo lygių skaičiu gausime reikšmingu matricos $\mathbf{M}_{k}$ elementų skaičiu $L_{r}$ padalinę iš jos stulpelių $I_{\check{z}}$ :

$$
L_{v}=\frac{L_{r}}{I_{\check{z}}}=\frac{\sum_{i=1}^{n} \sum_{j=1}^{m} \sum_{k=1}^{p} l_{i j k}}{\sum_{j=1}^{m} \sum_{k=1}^{p} Z_{j k}} ; i=\overline{1, n}, j=\overline{1, m, k}=\overline{1, p},
$$

čia $l_{i j k}$ - statybos i̇monès $k$-ojo baro matricos $\mathbf{M}_{k}$ $j$-ojo stulpelio $i$-asis reikšmingas elementas; $r_{j k}$ - statybos imonès $k$-ojo baro matricos $\mathbf{M}_{k} j$-asis stulpelis.

Mūsų nagrinèjamu atveju: $L_{n}=41 / 12=3,42$.

Vidutinę vertikalią atkarpą $L_{n}$ siūloma nustatinèti ir kitaip [6]:

$$
L_{v}=\sum_{l=1}^{k-2} \frac{A_{l} l}{A_{0}}, l=\overline{1, k-2},
$$

čia $A_{l}$ - darbu apimtis, kurią atliko įmonès padaliniai su valdymo lygiu skaičiumi $l ; A_{0}$ -

1 lentelé. Organizacijos valdymo sistema (pagal 1 pav.)

Table 1. Organization management system (according to Fig. 1)

\begin{tabular}{|c|c|cccc|}
\hline Eil. Nr. & Gamybinio padalinio numeris & Nurodymu grandinc (vertikali atkarpa) \\
\hline 1 & D1 & A & B1 & C1 & D1 \\
\hline 2 & D2 & A & B1 & C1 & D1 \\
\hline 3 & D4 & A & B1 & C2 & D4 \\
\hline 4 & D4 & A & B1 & C3 & D4 \\
\hline 5 & D1 & A & B1 & C3 & D5 \\
\hline 6 & D6 & A & B1 & C3 & D6 \\
\hline 7 & D7 & A & B2 & & D7 \\
\hline 8 & D8 & B2 & & D8 \\
\hline 9 & D1 & A & & C4 & D9 \\
\hline 10 & D10 & A & & C4 & D10 \\
\hline 11 & D11 & A & & C5 & D11 \\
\hline 12 & D12 & A & & D12 \\
\hline
\end{tabular}

bendra darbu apimtis, kurią atliko imoné; $k$ - bary skaičius įmonèje.

Šios metodikos autorius nurodo, $\operatorname{kad} L_{n}$ nustatymas pagal formulę (3) yra pranašesnis palyginus su skaičiavimais, besiremiančiais instanciju ar tarnybų skaičiumi. Privalumas pasireiškia tuo, kad labiau ivertinama ekonominè reikalo pusè, nes valdymo sistemos struktūros sudètingumas siejamas su jos mastais, jos pagrindiniy elementų ekonominiu "svoriu".

Mūsł nuomone, tokie argumentai ne visai pagrịsti. Pavyzdžiui, jeigu kitą ataskaitinị laikotarpị išaugs struktūrinių elementy dydis, taigi potencialios gali- 
mybès bei produkcijos kiekis, tai remiantis (3) formule gausime visai kitą $L_{v}$ reikšmę.

Vidutinę vertikalią atkarpą galima gauti taip pat remiantis (3) formulès modeliu:

$$
L_{v}=\sum_{l=1}^{k-2} \frac{L_{l} l}{L_{0}}
$$

čia $L_{1}$ - vertikaliu atkarpu skaičius su $l$ valdymo lygių; $L_{0}$ - bendras vertikaliu atkarpu skaičius matricoje $\mathbf{M}_{k}$ (stulpeliu skaičius matricoje $\mathbf{M}_{k}$ ); $k$ - vertikalių atkarpu su skirtingu hierarchinių valdymo lygių skaičiumi variantų kiekis.

Kaip minèta, kintant, didejant hierarchinių lygiụ skaičiui, atitinkamai kinta valdymo piramide - ji "plonejja". Ši procesą analogiškai vertikaliai atkarpai charakterizuoja vadinamoji valdymo atkarpa arba instancijai pavaldžių tarnybų, pareigybių ir pan. skaičius. Pastebetas toks desningumas: kai organizacijos dydis lieka toks pat, tai, kuo didesnè valdymo atkarpa, tuo mažiau lygių reikia formuoti [1]. Tai ir suprantama, kadangi viršininkas gali koordinuoti ir kontroliuoti tik ribotą pavaldinių skaičių Šiam išaugus ir peržengus viršininko pajęumo ribą, grupę būtina skaidyti ir sukurti dar vieną hierarchini lygi.

Imonès instancijų ir tarnybų skaičius, esantis tam tikrame VS hierarchiniame lygyje, gali būti labai ivairus. Dèl to sunku vienareikšmiai pasiūlyti matą ịmonei apskritai. Juo galètu būti arba organizacinių vienetų, tiesiogiai pavaldžių aukštesnei instancijai, skaičius (valdymo atkarpa), arba padaliniu skaičius žemiausiame hierarchiniame lygyje, arba vidutinis ju skaičius visuose lygiuose.

Valdymo atkarpos, kaip galimo konfigūracijos dalinio rodiklio, tenka atsisakyti, kadangi $\mathrm{ji}$ ar netgi vidutinis jos dydis negali apibūdinti nagrinejjamo vaizdo organizacijos mastu.

Padalinių skaičius žemiausiame hierarchiniame lygyje irgi visiškai neatskleidžia ir neịvertina instanciju ir tarnybų kiekio iqvairovès einant nuo vieno lygio prie kito.

Visų šiu trūkumų galima išvengti suradus vidutini visiems hierarchiniams valdymo lygiams instanciju ir tarnybu skaičiu $I_{n}$. Remiantis 2 pav., ieškomą dydi galima rasti taip:

$$
I_{v}=\frac{I_{r}}{H_{\max }}
$$

čia $I_{r}$ - įmonès valdymo sistemos instanciju ir tarnybu bendras skaičius; $H_{\max }$ - VS maksimalus hierarchiniu valdymo lygiụ skaičius.

Atveju, nurodytu 2 pav., $I_{n}=20 / 4=5,0$.

Dabar galime nustatyti abieju statybos imones valdymo struktūros konfigüracijos dalinių rodiklių tarpusavio priklausomybę:

$$
\begin{aligned}
& I_{v}=L_{v} \frac{I_{\tilde{z}} I_{r}}{H_{\max } L_{r}} ; \\
& L_{v}=I_{v} \frac{H_{\max } L_{r}}{I_{\check{z}} I_{r}} .
\end{aligned}
$$

Remdamiesi formulèmis (2) ir (5) nustatysime apibendrinančią imonès valdymo struktūros konfigūracijos charakteristiką. Tai galètų būti vidutinio hierarchinių lygiu ir vidutinio padalinių skaičiaus sandauga $K_{v}$. Tačiau ịvertinant tai, kad augant dydžiui $L_{v}, I_{v}$, kaip taisyklè, mažèja, skirtingoms valdymo struktūroms galime gauti vienodas ar panašios konfigūracijos rodiklio reikšmes. To išvengsime, jeigu apibendrinančia konfigūracijos dimensija parinksime ne jų sandaugą, o santykị.

Taigi pirmu atveju ieškomas rodiklis atrodys taip:

$$
K_{v}=L_{v} I_{v}=\frac{L_{r} I_{r}}{I_{\check{z}} H_{\max }}
$$

Valdymo sistemai, parodytai 2 pav.,

$$
K_{v}=3,42 \times 5=\frac{41 \times 20}{12 \times 4}=17,1 .
$$

Antru atveju rodikli $K_{v}$, remdamiesi formulemis (2) ir (5), skaičiuosime taip:

$$
K_{v}^{\prime}=\frac{L_{v}}{I_{v}}=\frac{L_{r} H_{\max }}{I_{\check{z}}-I_{r}} .
$$

Atvejui, parodytam 2 pav.,

$$
K_{v}^{\prime}=\frac{3,45}{5}=\frac{41 \times 4}{21 \times 20}=0,684 .
$$

Grafine (8) formulès interpretacija duota 3 pav. Kaip matome, dydis $K_{v}$ imonès piramidés pavidalo hierarchinę pareigybių struktūrą transformuoja i stačiakampi, kurio plotis yra lygus $L_{v} J_{v}$.

Dydžius $L_{v}$ ir $I_{v}$ atitinkančios didžiausios reikšmès yra 12 (padalinių skaičius žemiausiame hierarchiniame lygyje) ir 4 (maksimalus valdymo lygiu skaičius). Jų sandauga bus lygi: $K_{\max }=12 \times 4=48$. Jeigu paimsime $K_{v}$ ir $K_{\max }$ santyki $v$, tai gauname skaičių, kuris parodo, kiek faktiné imonès valdymo 


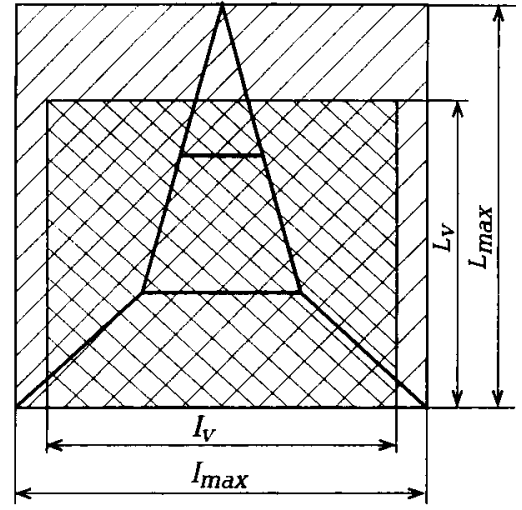

3 pav. Grafinè įmonès valdymo struktūros konfigūracijos rodiklio $K_{n}$ interpretacija

Fig. 3. Graphical interpretation of enterprise management structural configuration index $K_{n}$

sistema yra nutolusi nuo idealios vienalinijines:

$$
K_{v}^{\prime}=\frac{K_{v}}{K_{\max }} .
$$

Kuo didesnis šis santykis, tuo "statesnè" bus valdymo sistemą rodanti piramidé, t.y. tuo giliau bus suskaidyta pareigybių struktūra. Mūsų nagrinejjamu atveju (2 pav.)

$$
V=\frac{17,1}{48}=0356 .
$$

Kuris iš dvieju rodikliu $-K_{v}$ ar $K_{v}^{\prime}$ - tiksliau atspindi realybę, parodys empiriniai tyrimai.

\section{Išvados}

1. Konfigūracija, po specializavimosi ir veiklos koordinavimo, yra trečia îmonès valdymo struktūros dimensija. Ji apibūdina išorinę jos formą.

2. Konfigūracijos matavimui empiriniuose tyrimuose gali būti naudojami valdymo "piramidès" vidutinis skaidymo gylis ir plotis, kartais - santykiai tarp ivvairiu pareigybių.

3. Vidutini hierarchinių valdymo lygiu skaičiu gausime, jeigu ịmonès organigramą pertvarkysime prisitaikydami prie dabar vyraujančios vienalinijinès valdymo sistemos reikalavimų.

4. Vidutinị valdymo instancijų skaičiu viename hierarchiniame valdymo lygyje gausime visu instancijų kiekị padalinę iš didžiausio hierarchinio valdymo lygiu skaičiaus.

5. Apibendrinančiu i̇monès valdymo struktūros konfigūracijos rodikliu gali būti dviejų minètụ rodikliu sandauga arba santykis.

\section{Literatūra}

1. A.Keiser, H.Kubicek. Organisation 3. Vollig neu bearb. Aufl. - Berlin, New York de Gruter, 1992. 530 S.

2. A.Seilius. Firmos kūrimas ir valdymas. Klaipèda, 1994. $342 \mathrm{p}$.

3. M.Meskon, M.Albert, F.Khedouri. Management. 3rd. ed. No 4. Harpert Row. Publishers, 1988. 777 p.

4. Грейсон Джексон младший, О'Делг Карла. Американский менеджмент на пороге XXI века / Пер. с англ. М.: Экономика, 1991. 319 с.

5. Г.С.Одинцова. Организационное проектирование и планирование развития системы управления. Киев: Наукова думка, 1983. 160 с.

6. А.П. Климов. Экономическое обоснование вариантов структуры управления строительным производством. М.: Стройиздат, 1985. 128 с.

Itteikta 19960620

\section{A MEASUREMENT OF THE CONFIGURATION OF A BUILDING ENTERPRISE MANAGEMENT STRUCTURE}

\section{R.Ginevičius}

Su m m a r y

The configuration of a building enterprise management structure represents the outer form of a management system and is determined by two main principles of organizational formation, namely by specialization and coordination. The configuration may be measured by an organigram of an enterprise, i.e. by a graphical figure of a management system.

A management system can be quantitatively characterized by 2 values: an average number of hierarchical management level and an average number of institutions at one hierarchical level.

A generalized index of a building enterprise management structure configuration may be expressed by the product or ratio of the above-mentioned values. Which of them reflects better the real situation? Only an empirical investigation can reveal it.

Romualdas GINEVIČIUS. Doctor, Associate Professor. Dean of Business Management Faculty. Vilnius Gediminas Technical University, 11 Sauletekio Ave, 2040 Vilnius, Lithuania.

Dr degree in 1975 on problems of systems at Vilnius Civil Engineering Institute. Author of almost 100 articles and books. Member of Europe Sport Conference group "The Commerce in Sport", member of Technical sciences department of Lithuanian Academy of ICS. Research interests: analysis and formation of organizational administrating structures. 